This a pre-publication, uncorrected proof and is provided for information only. Accepted for publication in Epilepsy \& Behavior: ISSN: 1525-5050

\title{
The effectiveness and acceptability of a guided self-help Acceptance and Commitment Therapy (ACT) intervention for Psychogenic Non-Epileptic Seizures
}

Ruth Barrett-Naylora, David M Gresswell ${ }^{\mathrm{b}}$, David L Dawson ${ }^{\mathrm{b}}$

a Trent Doctorate in Clinical Psychology, University of Nottingham, YANG Fujia Building, B Floor, Jubilee Campus, Wollaton Road, Nottingham, NG8 1BB, UK.

b Trent Doctorate in Clinical Psychology, University of Lincoln, Brayford Wharf East, Lincoln, LN5 7AY,UK.

Correspondence should be addressed to: ruth.barrett-naylor@nhs.net

This work was supported by The University of Nottingham and the University of Lincoln 


\begin{abstract}
This study utilised a non-concurrent case-series design to examine the effectiveness and acceptability of a guided self-help Acceptance and Commitment Therapy (ACT) intervention for people with psychogenic nonepileptic seizures. A key aim of the study was to investigate the relationship between psychological flexibility (a key process within ACT), psychological health, quality of life and seizure frequency. Six participants completed the study, with reliable and clinically significant changes in psychological flexibility, quality of life and psychological health observed in the majority of participants. Notable reductions in self-reported seizure frequency were also observed. The implications of these findings for clinical practice are discussed and recommendations for future research suggested.
\end{abstract}

Key Words: Psychogenic non-epileptic seizure; case series; acceptance and commitment therapy; self-help. 


\section{Introduction}

Psychogenic non-epileptic seizures (PNES) bear a superficial resemblance to epileptic seizures; however, unlike epileptic seizures, PNES are not accompanied by abnormal electrical activity in the brain, and are thought in most cases to be an involuntary physical response to psychological phenomena $[1,2]$. The disorder affects 2-33 individuals per 100,000 [3] and between 20\%$30 \%$ of patients who attend epilepsy clinics are subsequently diagnosed with PNES [3-5].

The psychological impact of PNES is significant, with diagnosed individuals frequently experiencing higher levels of anxiety and depression [69], elevated risk of self-harm and suicidal ideation [8,10], and reduced functionality and poor life quality [2,11-13]. However, while PNES has been characterised as primarily a psychological condition, the specific aetiology of the disorder is not yet fully understood.

A variety of predisposing and precipitating factors in the histories of clients have been identified by clinical researchers across a range of studies, such as personal experience of trauma, anxiety and associated dissociation, somatization, previous loss of consciousness (such as during an illness or injury) [14-17], and broader psychological tendencies such as preferences for avoidant rather than active coping strategies $[7,18,19]$. In the most significant theoretical review to date, Brown and Reuber [20] critically examined extant theory and literature within the area and abstracted four broad mechanisms implicated in the development of PNES: (i) PNES as the manifestation of emotional distress; (ii) PNES as a hard-wired response (e.g., an intrinsic stress response); (iii) PNES as the activation of dissociated material (e.g., similar to flashbacks in trauma conditions); and (iv) PNES as a learned behaviour (e.g., directly or indirectly conditioned and operantly reinforced seizure-like behaviour). However, while each of these individual mechanisms is supported by an array of studies, none has sufficient specificity or sensitivity to explain the development and maintenance of the condition for all individuals.

Incorporating the review findings with their previous work on the Integrative Cognitive Model for Medically Unexplained Symptoms (MUS) [21], Brown and Reuber [20] propose that PNES result from the automatic activation of a specific type of dynamic mental representation which they term the "seizure 
scaffold". The authors suggest that the seizure scaffold contains cognitiveemotional-behavioural action programs that are developed through experience (such as observing seizures in others, experiencing trauma, previous loss of consciousness or illness, etc.) that interact with inherent behavioural response tendencies (such as hard-wired fear-escape responses), which are triggered in response to internal or external cues (such as trauma memories, autonomic arousal, conditioned stimuli, etc.). The model represents a significant theoretical development, providing an overarching account of PNES that coheres with previous theoretical and empirical work, while also offering an explanation for why some factors may be present within individuals diagnosed with PNES while absent in others. Importantly, the model also points to a number of areas that may be amenable to psychological intervention (see below).

Despite the significant impact PNES can have on an individual's psychological health and functioning, there is currently no consensus regarding the most appropriate or effective therapy for the condition. Cognitivebehavioural therapy (CBT) has been identified as a promising treatment, given the successful application of CBT to an expanding range of somatoform disorders, including chronic pain, chronic fatigue and medically unexplained symptoms (MUS) [22-24]. As such, CBT approaches to PNES are among the most robustly investigated [25-27], although only two controlled studies [28,29] and one RCT [30] have been conducted to date. Taken together, this research suggests that CBT can lead to a reduction in seizure frequency and beneficial improvements in depression and anxiety. However, while promising, the studies are limited both in terms of power and long-term follow up data. In addition, it also remains unclear how (e.g., through what psychological mechanisms) these interventions operate, which is crucial for developing effective psychological interventions that specifically target those factors identified as important in the development and maintenance of PNES.

Brown and Reuber [20] suggest that targeting cognitions (only) may not be useful for all individuals with PNES, but that other factors such as distress tolerance, emotional regulation, and interpersonal functioning should also be considered. Furthermore, the authors suggest that a "therapeutic environment that enables the individual to recognize, tolerate and accept the broader emotional dimension to their physical symptoms may be particularly important 
for these individuals" [20] (p67). A contemporary therapy that utilises acceptance and awareness-based strategies to facilitate functional behavioural change is Acceptance and Commitment Therapy (ACT). ACT is a third-wave cognitive-behaviour therapy that aims to reduce psychological suffering by encouraging values-based behaviour - that is, helping clients to live their life in a full and personally meaningful way, despite the difficulties associated with their specific condition. Unlike traditional CBT, ACT does not aim to change the content, frequency, or form of thoughts (e.g., cognitive restructuring); instead, ACT aims to foster psychological flexibility - "the ability to contact the present moment more fully as a conscious human being, and to change or persist in behavior when doing so serves valued ends" [31] (p.7) - in order to reduce experiential avoidance, and the limiting impact this can have on a person's behaviour.

From an ACT perspective, increased psychological flexibility helps to foster greater psychological awareness and cognitive distance; individuals are taught a range of strategies for 'noticing' and 'defusing' from the content of their thoughts and experiences in order to foster a sense of self that can observe these processes, without having to avoid, challenge, or ruminate upon them. These strategies allow the individual to pursue values-based activities, goals, and directions, even when experiencing distressing thoughts, feelings, or sensations [31]; this can help to replace the avoidance-based strategies that often underpin distressing psychological conditions, with active, purposeful, strategies instead. While the focus of most therapeutic intervention studies is to reduce or eliminate the frequency of a particular phenomenon (e.g., seizures), with quality of life or functionality generally considered important but secondary outcomes [6,25,32], ACT focuses primarily on helping individuals to 'live well' despite their condition. That is to say, if individuals diagnosed with PNES can be helped to lead more meaningful, functional lives, despite their seizures, then the negative impact of PNES may be lessened.

There is strong support for the efficacy of ACT for chronic medical conditions, including pain [33,34], cancer [35], diabetes [36], and epilepsy $[37,38]$, in addition to depression and anxiety-based psychological difficulties [39-42]. Furthermore, ACT has been successfully utilised with other MUS conditions $[43,44]$. However, no research to date has examined the utility of 
ACT for PNES specifically. Nonetheless, given that experiential avoidance, limited awareness, automatic (versus purposeful) behaviour, and heightened arousal have all been implicated in the development and maintenance of PNES, ACT (through the process of psychological flexibility) may offer additional therapeutic benefits to this population over and above those found previously using CBT. Indeed, in a recent systematic review and meta-analysis, ACT demonstrated superiority to CBT in nine of the sixteen studies reviewed, across a range of psychological and physical health presentations [45].

Poor engagement in psychological therapies has been reported for individuals with PNES, sometimes as a result of patients being understandably reluctant to attribute their seizures to psychological factors [46] or, for those that do access psychological support, because psychological therapy can be difficult, stressful, and can often trigger more seizures [47]. Self-help interventions may help to address some of these issues: such interventions can be undertaken alone, in a safe and familiar setting, at one's own pace, and without the need for broader acceptance or discussion of the diagnosis with others. There is growing support for the use of ACT delivered in a self-help format, with a recent systematic review reporting beneficial outcomes for anxiety and depression, with greater effect sizes reported for self-help interventions that incorporated an element of clinical guidance [48] (such as weekly check-in phone calls).

ACT as a therapeutic intervention for patients with PNES is untested; however, the theoretical applicability of an intervention such as ACT for this population, in which avoidance of internal states and disruptions to valuedbehaviour often occurs, appears promising, particularly given recent successful use of the therapy with other MUS client groups. Furthermore, given the successful use of ACT self-help in previous studies, this modality offers an interesting avenue of investigation for this specific population, given that other available psychological treatments and face-to face therapies can be experienced as aversive and can precipitate seizure occurrence. 


\subsection{Aims}

The purpose of this study was to examine the effectiveness and acceptability of a guided self-help ACT intervention for participants with PNES. Specifically, we aimed to investigate whether an ACT self-help intervention can lead to increased psychological flexibility in individuals diagnosed with PNES, and whether such changes relate to reliable and clinically significant change in psychological health and quality of life (primary outcomes). While ACT does not aim to target primary symptomology directly, we also wanted to examine whether the intervention had benefits in terms of reduction in seizure frequency (secondary outcome). Finally, we aimed to gauge participants' experience of the intervention through post-intervention change interviews.

\section{Method}

\subsection{Participants}

Following institutional ethical approval, the study was advertised through specific PNES social media support groups. After receiving detailed information about the research, potential participants who met the following inclusion criteria were recruited to the study: (1) $\geq 18$ and able to provide informed consent; (2) a confirmed diagnosis of PNES; (3) experienced $\geq 3$ psychogenic non-epileptic seizures within previous month; (4) not concurrently receiving, or about to receive, another psychotherapy; (5) good English reading and comprehension skills (assessed by the researcher in initial correspondence and telephone contact).

\subsection{Design}

The study utilised a non-concurrent case-series design [49]. Accordingly, no participant began the study at the same time (to satisfy the non-concurrent design) and recruitment continued until the recommended average of six participants (for case-series studies) was achieved [50].

\subsection{Measures}

Quality of life, psychological health, psychological flexibility, and seizure frequency measures were administered pre-intervention, post-intervention, and 
at 1-week and 1-month follow-up periods (Table 1). We opted to include two measures of psychological flexibility at the pre and post-intervention time points; while the AAQ has traditionally been the most widely used measure of psychological flexibility/experiential avoidance within ACT research, the discriminant and content validity of the tool has recently been questioned by a number of researchers [51-53]. Similarly, an adapted version of the AAQ for epilepsy is available [54]; however, comparisons between epilepsy and PNES groups are potentially problematic given the distinct profiles (and aetiologies) between the two conditions [12,13,55]. Accordingly, we also included the Comprehensive Assessment of Acceptance and Commitment Processes (CompACT) [52], which was developed to provide a broader measure of psychological flexibility that is more aligned to the underpinnings of the concept within ACT theory $[52,56]$. In addition to pre and post measurement, participants were also asked to complete the CompACT on a weekly basis in order to assess the cumulative effect of the intervention on psychological flexibility.

At the one month follow-up period, a change interview (adapted from Elliot) [57] was conducted by an independent researcher who was blinded to the outcomes of the study. The change interview was designed to assess participant's views of the self-help intervention, how they felt completing the intervention, their perception of any changes experienced during the intervention, and the possible reasons for any observed changes. 
Table 1. Psychometric properties and characteristics of measures

\begin{tabular}{|c|c|c|c|c|c|}
\hline Measure & Construct & No. items & Example item & $a$ & Scale range \& direction \\
\hline \multirow[t]{5}{*}{ DASS 21 [58] } & Overall distress & 21 & & .93 & $0-126$ \\
\hline & Depression & 7 & "I felt down hearted and blue" & .88 & $0-42$ \\
\hline & Anxiety & 7 & "I felt I was close to panic" & .82 & $0-42$ \\
\hline & Stress & 7 & "I tended to over react to situations" & .90 & $0-42$ \\
\hline & & & & & Higher score $=$ greater distress \\
\hline QOLIE 10 [59] & Quality of life & 10 & $\begin{array}{l}\text { "How much did your work/social } \\
\text { limitations bother you" } \\
\text { "How worried are you about having a } \\
\text { seizure" }\end{array}$ & .85 & $\begin{array}{c}10-50 \\
\text { Higher score }=\text { poorer QoL }\end{array}$ \\
\hline CompACT [52] & $\begin{array}{l}\text { Psychological } \\
\text { Flexibility }\end{array}$ & 23 & $\begin{array}{l}\text { "I find it difficult to stay focused on } \\
\text { what's happening in the present" } \\
\text { "I make choices based on what is } \\
\text { important to me, even if it is stressful" }\end{array}$ & .91 & $\begin{array}{c}25-137 \\
\text { Higher score }=\text { greater PF }\end{array}$ \\
\hline AAQ II [60] & $\begin{array}{l}\text { Psychological } \\
\text { Flexibility and } \\
\text { acceptance }\end{array}$ & 7 & "Emotions cause problems in my life" & .84 & $\begin{array}{c}7-49 \\
\text { Higher score }=\text { greater PF }\end{array}$ \\
\hline Seizure frequency & $\begin{array}{l}\text { Self-reported } \\
\text { seizure frequency }\end{array}$ & - & & - & - \\
\hline
\end{tabular}

Notes: DASS 21=depression anxiety \& stress scale; QOLIE-10=quality of life in epilepsy inventory; CompACT=comprehensive acceptance and commitment therapy processes; AAQ $\|=$ acceptance $\&$ action questionnaire; $\alpha=$ internal consistency; $\mathrm{PF}=$ psychological flexibility. 


\subsection{Intervention}

Participants received chapters and exercises from the ACT self-help book, Get out of your mind and into your life [61] over a six week period. Telephone support was provided by the first author once per week (for up to 30 minutes); this involved a discussion relating to the weeks' material and any difficulties the participant may have experienced during that period (including difficulties with understanding concepts or exercises, or any external life events that may have impacted on their ability to complete the self-help material). Table 2 provides a detailed overview of the intervention.

Table 2. Participant reading materials and the ACT process(es) targeted

\begin{tabular}{llll}
\hline \multicolumn{1}{c}{ Week } & \multicolumn{1}{c}{$\begin{array}{c}\text { ACT process } \\
\text { targeted }\end{array}$} & $\begin{array}{c}\text { Chapter } \\
\text { number }\end{array}$ & \multicolumn{1}{c}{ Chapter title(s) } \\
\hline $\begin{array}{l}\text { Baseline: Overview of } \\
\text { ACT given after initial } \\
\text { screen } \\
1\end{array}$ & N/A & Intro, 1,2 & $\begin{array}{l}\text { Introduction; Human suffering; Why } \\
\text { Language leads to suffering }\end{array}$ \\
& Acceptance & $3,4,9,10$ & $\begin{array}{l}\text { The Pull of Avoidance; Letting go; What } \\
\text { Willingness is and what it is not; } \\
\text { Willingness; Learning to Jump } \\
\text { The trouble with Thoughts; Having a } \\
\text { Thought vs. Buying a Thought } \\
\text { If I'm not my Thoughts, then Who Am I? } \\
3\end{array}$ \\
& Cognitive Defusion & 5,6 & $\begin{array}{l}\text { Mindfulness } \\
\text { What are Values?; Choosing Your }\end{array}$ \\
5 & $\begin{array}{l}\text { Self as Context } \\
\text { Present Moment } \\
\text { Awareness }\end{array}$ & 7 & $\begin{array}{l}\text { Values } \\
\text { Committing to Doing It }\end{array}$ \\
\hline
\end{tabular}

\subsection{Analysis}

We utilised Reliable Change Indices $(\mathrm{RCI})$ and Clinically Significant Change (CSC) statistics to examine whether the intervention lead to changes in our primary outcome measures. The $\mathrm{RCl}$ statistic is used to determine whether any change between an individual's pre and post-treatment scores is reliable, and is calculated by subtracting the pre-treatment score from the post-treatment score and then dividing the result by the 'standard error' (SE) of the difference of the measure used [62]. If the resulting value is within \pm 1.96 then the change is deemed reliable (at the 95\% confidence interval) [63].

If a reliable change is identified, then the post-treatment scores can be examined further for clinically significant change using criteria proposed by 
Jacobson and Truax [62]. CSC can be said to have occurred if either: the individual's post-treatment score is two standard deviations away from the mean of a clinical group (Criterion A); the individual's post-treatment score is two standard deviations within the mean of a non-clinical group (Criterion B); or the individual's post-treatment score is closer to the mean of the non-clinical group than the mean of the clinical group (Criterion C). Within the current study, we utilised criterion a or c, dependent on available comparative data [62]. Finally, we also examined weekly CompACT data using visual analysis to assess the cumulative effect of the intervention on psychological flexibility.

\section{Results}

\subsection{Sample}

Seven participants enrolled in the study; however, one participant withdrew after the third week and their data was not included in the subsequent analyses. Table 4 provides an overview of the results of all outcome measures.

Table 3 details the demographics of the remaining six participants. Table 4 provides an overview of the results of all outcome measures.

Table 3. Demographics of sample

\begin{tabular}{|c|c|c|c|c|c|c|c|c|}
\hline Participant & Age & Gender & $\begin{array}{l}\text { Current } \\
\text { Mental Health } \\
\text { Difficulties }\end{array}$ & $\begin{array}{l}\text { Previous } \\
\text { diagnosis } \\
\text { of } \\
\text { Epilepsy }\end{array}$ & $\begin{array}{l}\text { Current } \\
\text { diagnosis } \\
\text { of epilepsy }\end{array}$ & $\begin{array}{l}\text { PNES } \\
\text { diagnosis } \\
\text { received }\end{array}$ & $\begin{array}{l}\text { Medication } \\
\text { for PNES }\end{array}$ & $\begin{array}{l}\text { Previous } \\
\text { psychological } \\
\text { treatment }\end{array}$ \\
\hline 1 & 69 & M & No & No & No & $\begin{array}{l}\text { March } \\
2015\end{array}$ & No & No \\
\hline 2 & 24 & $\mathrm{~F}$ & Depression Anxiety & No & No & April 2016 & No & No \\
\hline 3 & 53 & $\mathrm{~F}$ & No & Yes & No & May 2013 & No & No \\
\hline 4 & 47 & $\mathrm{~F}$ & Anxiety & $\mathrm{N}$ & No & $\begin{array}{l}\text { November } \\
2015\end{array}$ & $\begin{array}{l}\text { Amitriptyline } \\
\text { (muscle } \\
\text { relaxant) }\end{array}$ & ISTDP \\
\hline 5 & 32 & $\mathrm{~F}$ & $\begin{array}{l}\text { No (reported } \\
\text { symptoms of } \\
\text { anxiety and } \\
\text { depression) }\end{array}$ & No & No & July 2015 & No & No \\
\hline 6 & 47 & $\mathrm{~F}$ & $\begin{array}{l}\text { Complex PTSD } \\
\text { Depression }\end{array}$ & Yes & No & 2012 & Klonopin & $\begin{array}{l}\text { Progressive } \\
\text { exposure }\end{array}$ \\
\hline
\end{tabular}


Notes: ISTDP=Intensive short term dynamic psychotherapy

All but one of the participants in the study were female and the average age of participants was 45.3 years $(S D=15.86)$. Two participants had previously received a diagnosis of epilepsy; however, their diagnosis was subsequently changed to PNES. Three participants reported having a mental health diagnosis (including anxiety, depression and/or PTSD) and one participant reported having symptoms of anxiety and depression. Two participants reported taking medication to help with their seizures and two participants reported receiving previous psychological therapy.

\subsection{Psychological Flexibility (CompACT \& AAQ-II)}

\subsubsection{Visual Analysis}

All participants demonstrated an improving upward trend in psychological flexibility (as measured by the weekly-administered CompACT) over the course of the intervention (Figure 1). However, no clear picture emerged between participants in terms of which intervention stage appeared to most influence the development of psychological flexibility; instead, development appeared to be a cumulative process, albeit with more rapid acquisition at different stages for individual participants.

\subsubsection{RCI \& CSC}

Participants 1 and 3 scored within the normal range for a non-distressed population on the CompACT prior to the intervention, and any subsequent improvements in their scores could therefore not be deemed reliable. Of the remaining four participants (P2, P4, P5, P6), all demonstrated reliable and clinically significant change on both the CompACT and AAQ which was maintained at follow-up. Overall, these changes were indicative of improvement; however, Participant 5 recorded both reliable and clinically significant improvement in psychological flexibility as measured by the CompACT, but also reliable and clinically significant deterioration as measured by the AAQ. While such a discrepancy between two measures that both purport to measure 
psychological flexibility is a concern, as highlighted above, the AAQ has been criticised in terms of face and discriminant validity, and it may be the case that the participant's score on this measure is reflective of these broader AAQ measurement issues.

\subsection{Psychological Health (DASS-21)}

Participants 1 and 3 also scored within the non-clinical range on this measure and any subsequent reliable improvement could therefore not have been determined. However, of the remaining four participants, all (P2, P4, P5, P6) demonstrated reliable and clinically significant improvement on the DASS21. However, while Participant 2 still evinced reliable improvement at 1-month follow-up, the clinical significance of this change did not meet CSC criteria. In addition, at follow-up, changes experienced by participant 6 did not meet $\mathrm{RCl}$ criteria; if they had, her scores would also have indicated a clinically significant improvement.

\subsection{Quality of Life (QOLIE-10)}

Participants 1 and 3 also scored within the normal range for quality of life prior to the intervention, and any subsequent improvements in QOLIE-10 scores could therefore not be deemed reliable. However, of the remaining participants, all four (P2, P4, P5, P6) demonstrated reliable improvement and three of these (P2, P4, P5) reached clinical significance. These improvements were maintained at both follow-up periods. 

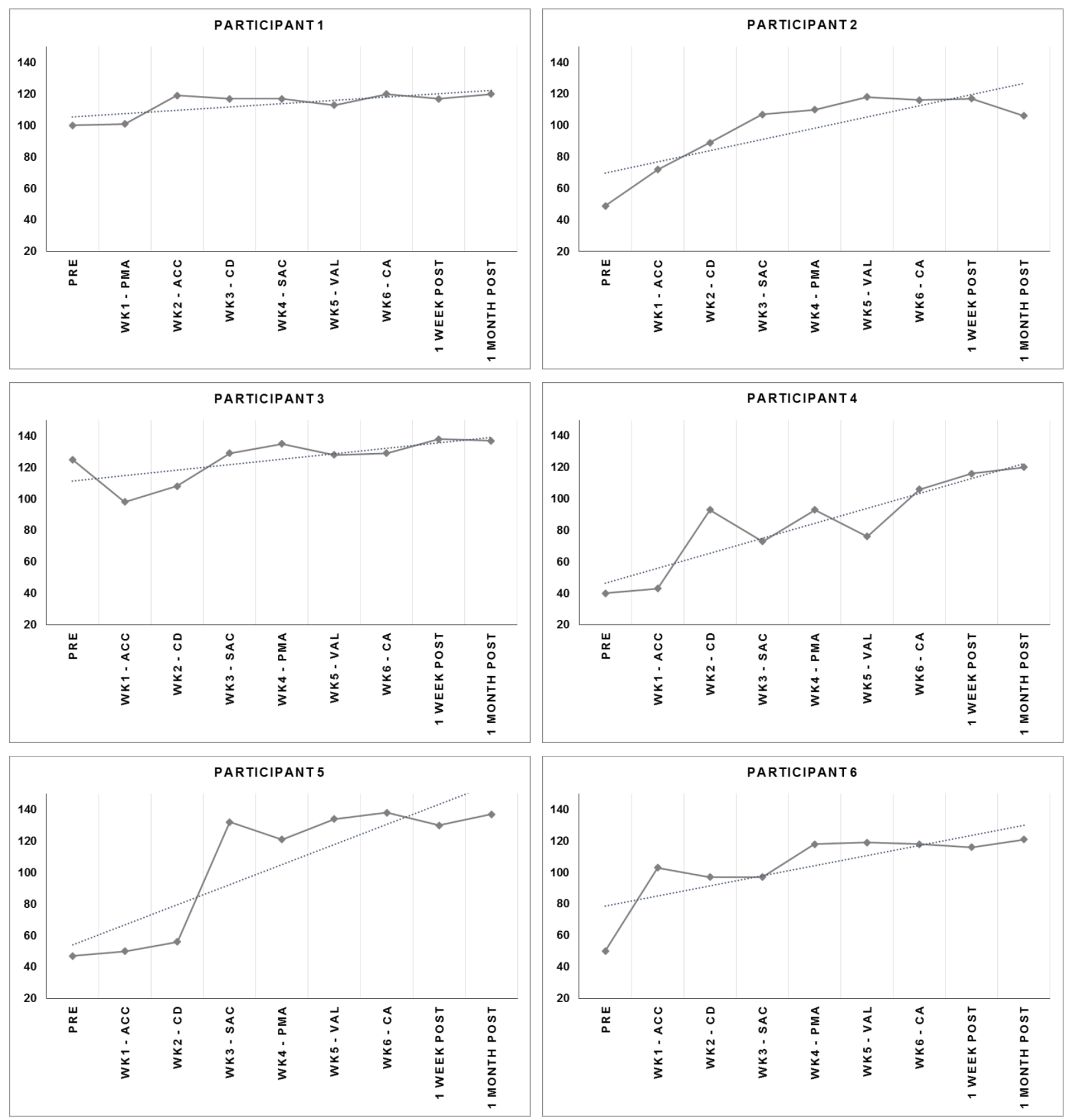

Figure 1. Psychological flexibility and trendline for each participant across study

Notes: PRE: Pre-intervention; WK: Week of intervention; ACC: Acceptance; CD: Cognitive Defusion; SAC: Self as Context; PMA: Present Moment Awareness; VAL: Values; CA: Committed Action; POST: Post-intervention follow-up 
Table 4. Results of the CompACT; AAQ-II; DASS-21; QOLIE-10; Weekly Seizure Frequency

\begin{tabular}{|c|c|c|c|c|}
\hline $\begin{array}{c}\text { Participant and } \\
\text { Measure } \\
\end{array}$ & Pre & Post & $\begin{array}{c}1 \text { week } \\
\text { Follow-up }\end{array}$ & $\begin{array}{l}1 \text { month } \\
\text { Follow-up }\end{array}$ \\
\hline \multicolumn{5}{|l|}{ P1 } \\
\hline CompACT & 100 & 120 & 117 & 120 \\
\hline AAQ-II & 12 & 12 & 10 & 10 \\
\hline DASS-21 & 10 & 10 & 6 & 10 \\
\hline QOLIE-10 & 16 & 12 & 10 & 14 \\
\hline Seizure Frequency & 2 & 0 & 1 & 4 \\
\hline \multicolumn{5}{|l|}{ P2 } \\
\hline CompACT & 49 & $116^{R+C+}$ & $117^{R+C+}$ & $106^{R+C+}$ \\
\hline AAQ-\|I & 26 & $12^{\mathrm{R}+}$ & $12^{R+}$ & $13^{R+}$ \\
\hline DASS-21 & 78 & $16^{R+C+}$ & $20^{R+C+}$ & $32^{R+}$ \\
\hline QOLIE-10 & 39 & $13^{R+C+}$ & $14^{R+C+}$ & $17^{\mathrm{R}+\mathrm{C}+}$ \\
\hline Seizure Frequency & 9 & 3 & 3 & 2 \\
\hline \multicolumn{5}{|l|}{ P3 } \\
\hline CompACT & 125 & 129 & 138 & 137 \\
\hline AAQ-II & 15 & 14 & 11 & 10 \\
\hline DASS-21 & 12 & 6 & 2 & 10 \\
\hline QOLIE-10 & 20 & 19 & 14 & 12 \\
\hline \multirow{2}{*}{\multicolumn{5}{|c|}{ P4 }} \\
\hline & & & & \\
\hline CompACT & 40 & $106^{R+C+}$ & $116^{R+C+}$ & $120^{R+C+}$ \\
\hline AAQ-II & 35 & $23^{R+}$ & $13^{R+}$ & $14^{\mathrm{R}+}$ \\
\hline DASS-21 & 68 & $30^{\mathrm{R}+}$ & $14^{R+C+}$ & $12^{R+C+}$ \\
\hline QOLIE-10 & 30 & $16^{\mathrm{R}+\mathrm{C}+}$ & $12^{\mathrm{R}+\mathrm{C}+}$ & $10^{\mathrm{R}+\mathrm{C}+}$ \\
\hline Seizure Frequency & 45 & 1 & 0 & 0 \\
\hline \multicolumn{5}{|l|}{ P5 } \\
\hline CompACT & 47 & $138^{R+C+}$ & $130^{R+C+}$ & $137^{\mathrm{R}+\mathrm{C}+}$ \\
\hline AAQ-\| & 29 & $7^{\text {R-c- }}$ & $7^{\text {R-C- }}$ & 7 R-C- \\
\hline DASS-21 & 56 & $16^{\mathrm{R}+\mathrm{c}+}$ & $10^{R+C+}$ & $2^{R+C+}$ \\
\hline QOLIE-10 & 31 & $19^{R+C+}$ & $19^{R+C+}$ & $15^{\mathrm{R}+\mathrm{C}+}$ \\
\hline Seizure Frequency & 10 & 4 & 6 & 0 \\
\hline \multicolumn{5}{|l|}{ P6 } \\
\hline CompACT & 50 & $118^{\mathrm{R}+\mathrm{C}+}$ & $116^{\mathrm{R}+\mathrm{C}+}$ & $121^{R+C+}$ \\
\hline AAQ-II & 28 & $20^{R+}$ & $12^{\mathrm{R}+}$ & $17^{\mathrm{R}+}$ \\
\hline DASS-21 & 34 & $18^{R+C+}$ & 28 & 24 \\
\hline QOLIE-10 & 35 & $29^{R+}$ & $33^{\mathrm{R}+}$ & $30^{R+}$ \\
\hline Seizure Frequency & 10 & 8 & 8 & 0 \\
\hline
\end{tabular}

Notes: ${ }^{\mathrm{R}}$ denotes Reliable Change and ${ }^{\mathrm{C}}$ denotes Clinically Significant Change (from clinical to non-clinical range) compared to pre-intervention scores at $p<.05$; + or - indicates improvement or deterioration, respectively. (N.B. all scales used criterion $C$ for clinical cut off except AAQ-II which used criterion A). Seizure frequency was self-reported by participants for the preceding week.

\subsection{Seizure Frequency}

A notable reduction in weekly seizure frequency was observed for four participants throughout the lifetime of the study (P2, P4, P5, P6), with 
participants 4, 5 and 6 reporting no seizures in the past week at one-month follow-up. While Participants 1 and 3 reported an initial reduction in seizures, this was not maintained at follow-up. Given that seizure frequency was measured by ideographic self-report, no RCI or CSC criteria could be applied.

\subsection{Change interview}

All participants who completed the study took part in a change interview at one-month follow-up (Table 5). Participants reported general positive changes throughout the study, such as feeling more accepting and mindful (P3, P4, P5 and P6), less avoidant (P1) and more confident (P2). All participants attributed changes to the intervention and reported that these changes were important to them. In relation to changes specific to seizures themselves, four participants reported either having less seizures or feeling differently towards them. Two participants reported no changes to their seizures which corresponded to the quantitative data collected (P1 \& P3).

The feedback indicated that most participants found the workbook easy to understand, although Participant 5 found the language difficult to grasp initially. Participant 1 also found the workbook less understandable due to the initial randomisation of chapters that we implemented within the design; this was subsequently changed for the remaining participants so that chapters were received sequentially. All participants said that they would recommend the book to others and two thirds described the mindfulness chapters as the most influential.

Three participants indicated that there were external events that may have impacted on the outcome of the study such as having an operation (P2), experiencing menopausal symptoms and family illness (P3) and Participant 1 reported that he felt he fitted the diagnosis of functional neurological disorder (FND) rather than PNES, which gave him hope whilst completing the study. All participants reported finding the telephone support useful.

During the screening process and at the time of the change interview, participants were asked to indicate the areas related to their seizures that were most important areas of change for them; for one participant, this domain remained the same at screening and at change interview (P1), however, all 
other participants reported a change in this area, with the majority indicating that quality of life was now the most important domain for them. 
Table 5. Participant's responses to Change Interview questions

\begin{tabular}{|c|c|c|c|c|c|c|c|c|c|c|c|c|}
\hline & \multirow[t]{2}{*}{ Understandable } & \multirow[t]{2}{*}{$\begin{array}{l}\text { Recommend } \\
\text { to others }\end{array}$} & \multirow[t]{2}{*}{ Influential chapter(s) } & \multirow[t]{2}{*}{ Overall Changes } & \multirow[t]{2}{*}{$\begin{array}{l}\text { Seizure } \\
\text { change }\end{array}$} & \multirow{2}{*}{$\begin{array}{l}\text { Surprised } \\
\text { by } \\
\text { changes }\end{array}$} & \multirow{2}{*}{$\begin{array}{l}\text { Attribute } \\
\text { to work } \\
\text { book }\end{array}$} & \multirow[t]{2}{*}{$\begin{array}{l}\text { Importance } \\
\text { of changes }\end{array}$} & \multicolumn{2}{|c|}{$\begin{array}{l}\text { Most important area } \\
\text { of life }\end{array}$} & \multirow[t]{2}{*}{ Ext event } & \multirow[t]{2}{*}{$\begin{array}{c}\text { Therapist } \\
\text { support }\end{array}$} \\
\hline & & & & & & & & & Pre- & Now & & \\
\hline $\mathrm{P} 1$ & $\begin{array}{l}\text { No-chapters } \\
\text { were sent out in } \\
\text { batches }\end{array}$ & Yes & Committed action/ Values & Less avoidant & No & Neutral & $\begin{array}{l}\text { Highly } \\
\text { likely }\end{array}$ & Important & $\begin{array}{l}\text { Mental } \\
\text { function }\end{array}$ & $\begin{array}{l}\text { Mental } \\
\text { function }\end{array}$ & $\begin{array}{l}\text { Yes: } \\
\text { Possible } \\
\text { FND }\end{array}$ & Helpful \\
\hline P2 & Yes & Yes & Mindfulness & $\begin{array}{l}\text { Coping skills } \\
\text { Built confidence }\end{array}$ & $\begin{array}{l}\text { Yes - } \\
\text { attitude }\end{array}$ & $\begin{array}{l}\text { Quite } \\
\text { surprised }\end{array}$ & Neutral & $\begin{array}{l}\text { Very } \\
\text { important }\end{array}$ & $\begin{array}{c}\text { Daily } \\
\text { activities }\end{array}$ & $\begin{array}{l}\text { Mental } \\
\text { function }\end{array}$ & $\begin{array}{c}\text { Yes: } \\
\text { Operation }\end{array}$ & $\begin{array}{l}\text { Helpful \& } \\
\text { supportive }\end{array}$ \\
\hline P3 & Yes & Yes & $\begin{array}{c}\text { Acceptance/ } \\
\text { Mindfulness Cognitive } \\
\text { defusion }\end{array}$ & $\begin{array}{l}\text { More aware of } \\
\text { thoughts } \\
\text { Generally } \\
\text { feeling better }\end{array}$ & No & $\begin{array}{l}\text { Quite } \\
\text { surprised }\end{array}$ & $\begin{array}{l}\text { Highly } \\
\text { likely }\end{array}$ & $\begin{array}{l}\text { Very } \\
\text { important }\end{array}$ & $\begin{array}{c}\text { Daily } \\
\text { activities }\end{array}$ & QOL & $\begin{array}{c}\text { Yes } \\
\text { Menopause/ } \\
\text { familial } \\
\text { illness }\end{array}$ & $\begin{array}{l}\text { Helpful \& } \\
\text { supportive }\end{array}$ \\
\hline P4 & Yes & Yes & $\begin{array}{c}\text { Role of language } \\
\text { Mindfulness } \\
\text { Values }\end{array}$ & $\begin{array}{l}\text { "actively } \\
\text { engaged in the } \\
\text { present } \\
\text { moment" }\end{array}$ & $\begin{array}{l}\text { Yes - less } \\
\text { of them }\end{array}$ & $\begin{array}{l}\text { Neutral to } \\
\text { quite } \\
\text { surprised }\end{array}$ & $\begin{array}{l}\text { Highly } \\
\text { likely }\end{array}$ & $\begin{array}{l}\text { Very } \\
\text { important }\end{array}$ & Mood & QOL & No & $\begin{array}{l}\text { Helpful \& } \\
\text { supportive }\end{array}$ \\
\hline P5 & $\begin{array}{l}\text { Not at first - } \\
\text { language was } \\
\text { difficult }\end{array}$ & Yes & Mindfulness & More accepting & $\begin{array}{l}\text { Yes - less } \\
\text { of them }\end{array}$ & $\begin{array}{c}\text { Very } \\
\text { surprised }\end{array}$ & $\begin{array}{l}\text { Highly } \\
\text { likely }\end{array}$ & $\begin{array}{l}\text { Very } \\
\text { important }\end{array}$ & $\begin{array}{l}\text { Mental } \\
\text { function }\end{array}$ & QOL & No & $\begin{array}{l}\text { Helpful \& } \\
\text { supportive }\end{array}$ \\
\hline P6 & Yes & Yes & Cognitive defusion & $\begin{array}{l}\text { More accepting, } \\
\text { feel free }\end{array}$ & $\begin{array}{l}\text { No but less } \\
\text { bothered } \\
\text { by them }\end{array}$ & $\begin{array}{l}\text { Quite } \\
\text { surprised }\end{array}$ & Likely & $\begin{array}{l}\text { Very } \\
\text { important }\end{array}$ & $\begin{array}{c}\text { Daily } \\
\text { activities }\end{array}$ & QOL & No & Helpful \\
\hline
\end{tabular}

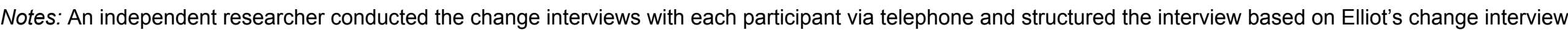
schedule [57]. Ext event= influential external events during the study; $Q O L=$ quality of life. 


\section{Discussion}

This study investigated the effectiveness and acceptability of a guided selfhelp ACT intervention for participants with PNES, with particular focus on psychological flexibility, psychological health, and quality of life, and whether the intervention had secondary gains in terms of seizure frequency.

An increase is psychological flexibility was observed for all participants over the course of the intervention, indicating that the self-help format successfully targeted expected ACT processes. While changes in psychological flexibility were only clinically significant and reliable for four participants, the remaining two participants (P1 \& P3) already had elevated pre-treatment scores, and therefore only reliable and clinically significant deterioration could feasibly have been observed for these participants due to this ceiling effect. For the four participants who could and did demonstrate significant and reliable improvement in psychological flexibility, these changes were also observed at both follow-up periods, suggesting the ACT intervention had a significant impact on increasing psychological flexibility in the longer term, despite representing a relatively brief, 'low dose' of the therapy. This is in line with broader findings that have found self-help ACT to be useful for patients with medically unexplained symptoms [44], particularly when the intervention is accompanied by brief clinician support [48].

Those participants who demonstrated meaningful change in levels of psychological flexibility also reported improvements in psychological health and quality of life, providing further support for psychological flexibility as a key, transdiagnostic mediator of change in ACT therapy [64]. Of particular note, while not directly targeted, these participants also reported fewer seizures post-intervention. Although seizure frequency was measured by self-report, and frequency can undulate over time (and hence changes from baseline to follow-up may be an artefact of mismeasurement), taken together with evidence from the change interviews, this finding does cohere with previous research that suggests psychological flexibility can function to reduce experiential avoidance (which in turn has been highlighted as a potentially significant maintenance factor of seizures in PNES $[7,18])$.

The two participants (P1 \& P3) who did not achieve reliable or clinically significant changes in psychological flexibility also reported no significant changes in quality of life, psychological health or seizure frequency. While this initially appears 
to cohere with ACT theory, it is important to highlight that both participants reported high levels of psychological flexibility prior to and throughout the course of the study, and therefore the lack of change in the other measured outcomes cannot be directly attributed to low levels of psychological flexibility. This may suggest that changes in psychological flexibility alone are not sufficient to improve related outcomes; however, given this was not the case for the other four participants, it may be that this finding is related to measurement effects, such as a lack of sensitivity in the CompACT at the higher end of the scale, or the specific response style of the two participants. It may also indicate that a lack of variability in psychological flexibility measurement can in itself be a potential indicator of psychological fixedness; such measures require an individual to be able to reflect on their current thoughts, feelings, and behaviour from a 'defused' perspective, and if such a perspective is difficult for an individual to achieve, the resultant measurement is likely to be impacted.

Overall, the ACT self-help intervention appeared effective in producing positive outcomes in psychological flexibility, psychological health, quality of life, and reduced seizure frequency for the majority of participants, supporting previous positive findings of the use of self-help ACT interventions with patients diagnosed with a MUS $[44,65]$. Improvements in psychological flexibility and seizure frequency were clearly replicated across four participants, and improvements relating to quality of life and psychological health were replicated across three participants. The replication of these intervention effects across cases meets published evidence standards criteria [66] and supports the use of an ACT guided self-help intervention for a PNES population. Furthermore, participant reports also indicated that the intervention was acceptable, generally well-received, and led to meaningful changes for the majority of participants.

While preliminary, these findings suggest that psychological flexibility may offer an important treatment target within PNES, and that the strategies learned within ACT that foster psychological flexibility (such as acceptance and experiential engagement) may function to disrupt the activation of the "seizure scaffold" proposed by Brown and Reuber [20]. Such a proposal has theoretical coherence given that psychological flexibility aims to reduce experiential avoidance, improve cognitive and bodily awareness, and encourages the active acceptance of aversive sensations and states (when doing so serves valued ends), all of which could be argued to reduce 
the likelihood of the seizure scaffold activating within Brown and Reuber's model. Specific examination of the relationship between psychological flexibility and the Integrated Cognitive Model of PNES in future research may therefore be beneficial.

The current study did not modify the self-help materials in any way which has implications for the conclusions that can be drawn. The book chapters were not randomised, which limits the inferences that can be drawn from the effects of specific chapters (and the hypothesised change processes therein) on the development of psychological flexibility; observed improvements may be the result of carryover effects from previous chapters rather than the chapter of interest. However, there were no clear indications across participants in relation to which chapters/processes appeared to most foster psychological flexibility. While randomisation of the chapters was initially instigated to examine whether specific chapters/processes appeared particularly useful for improving psychological flexibility in this population, this was withdrawn from the study design following feedback from the first participant who reported difficulty in completing chapters out of sequence. Future research may consider slight adaptations to the self-help book that would allow randomisation of chapters without disrupting the overall narrative of the book, and thus the examination of the differential impact of specific chapters/processes.

The design of the intervention also made it difficult to determine whether the observed therapeutic changes were a result of a specific process or stage within the intervention, other, non-specific factors (such as the relationship between participant and researcher), the cumulative effect of receiving chapters, or a broader Hawthorne effect. The change interviews were included to explore these issues in more detail; however, the resulting data provided a mixed picture, indicating that the workbook, therapist support, and external factors were all considered to play a part by participants. Future research could examine these areas further by exploring the benefits of the intervention with and without telephone support (although recent research in this area suggests that supported ACT self-help is most efficacious [48]) and also the potential impact of the therapeutic alliance on observed effects. Finally, given the above findings, it appears that a feasibility randomised control trial would be warranted as a next step, which would provide a method for controlling for external life events (between groups), while also providing effect size estimates for a full clinical trial of the intervention. 


\subsection{Conclusions}

The findings support the use of guided self-help ACT intervention for people diagnosed with PNES. A self-help intervention may provide an alternative, low cost treatment approach that has the potential benefits of widening access to therapeutic interventions for this population [67], while reducing some of the risks of attending face to face therapy that can be experienced by this group (such as within session seizures [47]. However, the findings outlined here could be further supported by: (1) longer term follow-up to examine treatment effects after six and twelve months; (2) examining the differences between those participants that showed changes in outcomes and those that did not, given the similar elevated levels of psychological flexibility across all participants; (3) a larger controlled study comparing ACT to CBT for this population, to examine whether the changes observed here are replicated, and whether treatment effects are superior to other psychological interventions.

Declaration of interest: None

Funding: This research did not receive any specific grant from funding agencies in the public, commercial, or not-for-profit sectors. 


\section{References}

[1] Marchetti RL, Kurcgant D, Neto JG, von Bismark MA, Marchetti LB, Fiore LA. Psychiatric diagnoses of patients with psychogenic non-epileptic seizures. Seizure 2008;17:247-53.

[2] Szaflarski JP, Hughes C, Szaflarski M, Ficker DM, Cahill WT, Li M, et al. Quality of Life in Psychogenic Nonepileptic Seizures. Epilepsia 2003;44:23642. doi:10.1046/j.1528-1157.2003.35302.x.

[3] Brown RJ, Syed TU, Benbadis SR, LaFrance Jr. WC, Reuber M. Psychogenic nonepileptic seizures. Futur Clin Epilepsy Res 2011;22:85-93.

doi:http://dx.doi.org.proxy.library.lincoln.ac.uk/10.1016/j.yebeh.2011.02.016.

[4] Benbadis SR, Allen HW, Hauser WA. An estimate of the prevalence of psychogenic non-epileptic seizures. Seizure 2000;9:280-1.

[5] Griffith NM, Szaflarski JP. Epidemiology and classification of psychogenic nonepileptic seizures. In: Schachter SC, LaFrance Jr. WC, editors. Gates and Rowan's Nonepileptic Seizures. 3rd ed., Cambridge University Press; 2010, p. 3-16.

[6] Bodde NMG, Brooks JL, Baker GA, Boon PAJM, Hendriksen JGM, Mulder $\mathrm{OG}$, et al. Psychogenic non-epileptic seizures--definition, etiology, treatment and prognostic issues: a critical review. Seizure 2009;18:543-53. doi:10.1016/j.seizure.2009.06.006.

[7] Dimaro L V, Dawson DL, Moghaddam NG, Roberts NA, Brown I, Reuber M. Anxiety and avoidance in psychogenic nonepileptic seizures: The role of implicit and explicit anxiety. Epilepsy Behav 2014;33:77-86. doi:10.1016/j.yebeh.2014.02.016.

[8] Duncan R, Razvi S, Mulhern S. Newly presenting psychogenic nonepileptic seizures: incidence, population characteristics, and early outcome from a prospective audit of a first seizure clinic. Epilepsy Behav 2011;20:308-11. doi:10.1016/j.yebeh.2010.10.022.

[9] Selkirk M, Duncan R, Oto M, Pelosi A. Clinical differences between patients with nonepileptic seizures who report antecedent sexual abuse and those who do not. Epilepsia 2008;49:1446-50. doi:10.1111/j.1528-1167.2008.01611.x.

[10] Ettinger AB, Devinsky O, Weisbrot DM, Ramakrishna RK, Goyal A. A Comprehensive Profile of Clinical, Psychiatric, and Psychosocial 
Characteristics of Patients with Psychogenic Nonepileptic Seizures. Epilepsia 1999;40:1292-8. doi:10.1111/j.1528-1157.1999.tb00860.x.

[11] LaFrance Jr. WC, Benbadis SR. Avoiding the costs of unrecognized psychological nonepileptic seizures. Neurology 2006;66:1620-1. doi:66/11/1620 [pii].

[12] Mercer G, Martin RC, Reuber M. Health related quality of life: utility and limitation in patients with psychogenic nonepileptic seizures. In: Schachter SC, LaFrance Jr. WC, editors. Gates and Rowan's Nonepileptic Seizures. 3rd ed., Cambridge University Press; 2010, p. 149-56.

[13] Testa SM, Schefft BK, Szaflarski JP, Yeh H-S, Privitera MD. Mood, Personality, and Health-related Quality of Life in Epileptic and Psychogenic Seizure Disorders. Epilepsia 2007;48:973-82.

[14] Salmon P, Al-Marzooqi SM, Baker G, Reilly J. Childhood family dysfunction and associated abuse in patients with nonepileptic seizures: towards a causal model. Psychosom Med 2003;65:695-700.

[15] Barry JJ, Sanborn K. Etiology, diagnosis, and treatment of nonepileptic seizures. Curr Neurol Neurosci Rep 2001;1:381-9.

[16] Fiszman A, Alves-Leon SV, Nunes RG, Isabella D, Figueira I. Traumatic events and posttraumatic stress disorder in patients with psychogenic nonepileptic seizures: a critical review. Epilepsy Behav 2004;5:818-25.

[17] Brown RJ, Reuber M. Psychological and psychiatric aspects of psychogenic non-epileptic seizures (PNES): a systematic review. Clin Psychol Rev 2016;45:157-82.

[18] Goldstein LH, Mellers JDC. Ictal symptoms of anxiety, avoidance behaviour, and dissociation in patients with dissociative seizures. J Neurol Neurosurg Psychiatry 2006;77:616-21.

[19] Goldstein LH, Drew C, Mellers JDC, Mitchell-O'Malley S, Oakley DA. Dissociation, hypnotizability, coping styles and health locus of control: characteristics of pseudoseizure patients. Seizure 2000;9:314-22. doi:10.1053/seiz.2000.0421.

[20] Brown RJ, Reuber M. Towards an integrative theory of psychogenic nonepileptic seizures (PNES). Clin Psychol Rev 2016;47:55-70. doi:10.1016/j.cpr.2016.06.003.

[21] Brown RJ. Psychological mechanisms of medically unexplained symptoms: an 
integrative conceptual model. Psychol Bull 2004;130:793.

[22] Kroenke K, Swindle R. Cognitive-behavioral therapy for somatization and symptom syndromes: a critical review of controlled clinical trials. Psychother Psychosom 2000;69:205-15.

[23] Deary V, Chalder T, Sharpe M. The cognitive behavioural model of medically unexplained symptoms: a theoretical and empirical review. Clin Psychol Rev 2007;27:781-97.

[24] Henningsen P, Zipfel S, Herzog W. Management of functional somatic syndromes. Lancet 2007;369:946-55.

[25] Kuyk J, Siffels MC, Bakvis P, Swinkels WAM. Psychological treatment of patients with psychogenic non-epileptic seizures: An outcome study. Seizure 2008;17:595-603. doi:http://dx.doi.org/10.1016/j.seizure.2008.02.006.

[26] LaFrance Jr. WC, Devinsky O. The treatment of nonepileptic seizures: historical perspectives and future directions. Epilepsia 2004;45 Suppl 2:15-21. doi:10.1111/j.0013-9580.2004.452002.x [doi].

[27] Goldstein LH, LaFrance Jr. WC, Chigwedere C, Mellers JDC, Chalder T. Cognitive behaviour treatments. In: Schachter SC, LaFrance Jr. WC, editors. Gates and Rowan's Nonepileptic Seizures. 3rd ed., Cambridge University Press; 2010, p. 281-8.

[28] Goldstein LH, Deale AC, Mitchell-O'Malley SJ, Toone BK, Mellers JDC. An evaluation of cognitive behavioral therapy as a treatment for dissociative seizures: a pilot study. Cogn Behav Neurol 2004;17:41-9.

[29] LaFrance Jr. WC, Miller IW, Ryan CE, Blum AS, Solomon DA, Kelley JE, et al. Cognitive behavioral therapy for psychogenic nonepileptic seizures. Epilepsy Behav 2009;14:591-6.

[30] Goldstein LH, Chalder T, Chigwedere C, Khondoker MR, Moriarty J, Toone BK, et al. Cognitive-behavioral therapy for psychogenic nonepileptic seizures: a pilot RCT. Neurology 2010;74:1986-94. doi:10.1212/WNL.0b013e3181e39658 [doi].

[31] Hayes SC, Luoma JB, Bond FW, Masuda A, Lillis J. Acceptance and Commitment Therapy: Model, processes and outcomes. Behav Res Ther 2006;44:1-25. doi:http://dx.doi.org/10.1016/j.brat.2005.06.006.

[32] Baslet G. Psychogenic nonepileptic seizures: a treatment review. What have we learned since the beginning of the millennium? Neuropsychiatr Dis Treat 
2012;8:585-98. doi:10.2147/NDT.S32301.

[33] Robinson P, Hayes SC. Acceptance and commitment: A model for integration. In: Cummings NA, Cummings JL, Johnson J, Madison CT, editors. Behav. Heal. Prim. care A Guid. Clin. Integr., Madison, CT: Psychological Press; 1997, p. 177-203.

[34] Wetherell JL, Afari N, Rutledge T, Sorrell JT, Stoddard JA, Petkus AJ, et al. A randomized, controlled trial of acceptance and commitment therapy and cognitive-behavioral therapy for chronic pain. Pain 2011;152:2098-107. doi:10.1016/j.pain.2011.05.016.

[35] Feros DL, Lane L, Ciarrochi J, Blackledge JT. Acceptance and Commitment Therapy (ACT) for improving the lives of cancer patients: a preliminary study. Psycho-oncology 2013;22:459-64.

[36] Gregg JA, Callaghan GM, Hayes SC, Glenn-Lawson JL. Improving diabetes self-management through acceptance, mindfulness, and values: a randomized controlled trial. J Consult Clin Psychol 2007;75:336.

[37] Lundgren T, Dahl J, Melin L, Kies B. Evaluation of Acceptance and Commitment Therapy for Drug Refractory Epilepsy: A Randomized Controlled Trial in South Africa-A Pilot Study. Epilepsia (Series 4) 2006;47:2173-9. doi:10.1111/j.1528-1167.2006.00892.x.

[38] Lundgren T, Dahl J, Yardi N, Melin L. Acceptance and Commitment Therapy and yoga for drug-refractory epilepsy: a randomized controlled trial. Epilepsy Behav 2008;13:102-8.

[39] Forman EM, Herbert JD, Moitra E, Yeomans PD, Geller PA. A Randomized Controlled Effectiveness Trial of Acceptance and Commitment Therapy and Cognitive Therapy for Anxiety and Depression. Behav Modif 2007;31:772-99. doi:10.1177/0145445507302202.

[40] Bohlmeijer ET, Fledderus M, Rokx TAJJ, Pieterse ME. Efficacy of an early intervention based on acceptance and commitment therapy for adults with depressive symptomatology: Evaluation in a randomized controlled trial. Behav Res Ther 2011;49:62-7. doi:10.1016/j.brat.2010.10.003.

[41] Dalrymple KL, Herbert JD. Acceptance and Commitment Therapy for Generalized Social Anxiety Disorder: A Pilot Study . Behav Modif 2007;31:543-68. doi:10.1177/0145445507302037.

[42] Hofmann SG, Sawyer AT, Witt AA, Oh D. The Effect of Mindfulness-Based 
Therapy on Anxiety and Depression: A Meta-Analytic Review. J Consult Clin Psychol 2010;78:169-83. doi:10.1037/a0018555.

[43] Wicksell RK, Kemani M, Jensen K, Kosek E, Kadetoff D, Sorjonen K, et al. Acceptance and commitment therapy for fibromyalgia: a randomized controlled trial. Eur J Pain 2013;17:599-611.

[44] Roche L, Dawson DL, Moghaddam NG, Abey A, Gresswell DM. An Acceptance and Commitment Therapy (ACT) intervention for Chronic Fatigue Syndrome (CFS): A case series approach. J Context Behav Sci 2017;6:17886. doi:10.1016/j.jcbs.2017.04.007.

[45] Ruiz FJ. Acceptance and commitment therapy versus traditional cognitive behavioral therapy: A systematic review and meta-analysis of current empirical evidence. Int J Psychol Psychol Ther 2012;12:333-58.

[46] Moore PM, Baker GA, McDade G, Chadwick D, Brown SW. Epilepsy, pseudoseizures and perceived family characteristics: a controlled study. Epilepsy Res 1994;18:75-83.

[47] Howlett S, Reuber M. An augmented model of brief psychodynamic interpersonal therapy for patients with nonepileptic seizures. Psychother Theory, Res Pract Train 2009;46:125-38.

[48] French K, Golijani-Moghaddam N, Schroder T. What is the Evidence for the Efficacy of Self-Help Acceptance and Commitment Therapy? A Systematic Review and Meta-Analysis. 2017. doi:10.1016/j.jcbs.2017.08.002.

[49] Barlow DH, Nock MK, Hersen M. Single case experimental designs: Strategies for studying behavior for change. 3rd ed. New York: Allyn \& Bacon; 2009.

[50] Smith JD. Single-case experimental designs: A systematic review of published research and current standards. Psychol Methods 2012;17:510.

[51] Wolgast M. What Does the Acceptance and Action Questionnaire (AAQ-II) Really Measure? Behav Ther 2014;45:831-9.

[52] Francis AW, Dawson DL, Golijani-Moghaddam N. The development and validation of the Comprehensive assessment of Acceptance and Commitment Therapy processes (CompACT). J Context Behav Sci 2016;5:134-45. doi:10.1016/j.jcbs.2016.05.003.

[53] Waldeck D, Tyndall I, Riva P, Chmiel N. How do we cope with ostracism? Psychological flexibility moderates the relationship between everyday ostracism experiences and psychological distress. J Context Behav Sci 
2017;6:425-32.

[54] Lundgren T, Dahl J, Hayes SC. Evaluation of mediators of change in the treatment of epilepsy with acceptance and commitment therapy. J Behav Med 2008;31:225-35.

[55] Szaflarski JP, Szaflarski M. Seizure disorders, depression, and health-related quality of life. Epilepsy Behav 2004;5:50-7. doi:10.1016/j.yebeh.2003.10.015.

[56] Hayes SC, Villatte M, Levin M, Hildebrandt M. Open, aware, and active: Contextual approaches as an emerging trend in the behavioral and cognitive therapies. Annu Rev Clin Psychol 2011;7:141-68.

[57] Elliott R. Psychotherapy change process research: Realizing the promise. Psychother Res 2010;20:123-35.

[58] Lovibond SH, Lovibond PF. Manual for the depression anxiety stress scales. Sydney: Psychology Foundation; 1995.

[59] Cramer JA, Perrine K, Devinsky O, Meador K. A Brief Questionnaire to Screen for Quality of Life in Epilepsy The QOLIE-10. Epilepsia 1996;37:577-82.

[60] Bond FW, Hayes SC, Baer RA, Carpenter KM, Guenole N, Orcutt HK, et al. Preliminary Psychometric Properties of the Acceptance and Action Questionnaire-II: A Revised Measure of Psychological Inflexibility and Experiential Avoidance. Behav Ther 2011;42:676-88. doi:10.1016/j.beth.2011.03.007.

[61] Hayes SC, Smith S. Get out of your mind and into your life: The new acceptance and commitment therapy. New Harbinger Publications; 2005.

[62] Jacobson NS, Truax P. Clinical significance: a statistical approach to defining meaningful change in psychotherapy research. J Consult Clin Psychol 1991;59:12-9.

[63] Morley S. Single Case Methods in Clinical Psychology: A Practical Guide. Routledge; 2017.

[64] Ciarrochi J, Bilich L, Godsell C. Psychological flexibility as a mechanism of change in acceptance and commitment therapy. Assess Mindfulness Accept Process Clients Illum Theory Pract Chang 2010:51-75.

[65] Baslet G, Hill J. Case report: Brief mindfulness-based psychotherapeutic intervention during inpatient hospitalization in a patient with conversion and dissociation. Clin Case Stud 2011;10:95-109.

[66] Kratochwill TR, Hitchcock J, Horner RH, Levin JR, Odom SL, Rindskopf DM, et 
al. Single-case designs technical documentation. What Work Clear 2010.

[67] Cuijpers P, Donker T, van Straten A, Li J, Andersson G. Is guided self-help as effective as face-to-face psychotherapy for depression and anxiety disorders? A systematic review and meta-analysis of comparative outcome studies. Psychol Med 2010;40:1943-57. 